\title{
Sharing or not sharing? Balancing uncertainties after cancer in urban Norway
}

Tone Seppola-Edvardsen*a, Rikke Sand Andersen ${ }^{\mathrm{b}}$ and Mette Bech Risør ${ }^{\mathrm{a}}$

${ }^{a}$ General Practice Research Unit, Department of Community Medicine, The Arctic University of Norway, Tromsø, Norway and ${ }^{\mathrm{b}}$ Research Unit for General Practice, Research Centre for Cancer Diagnosis in Primary Care and Department of Anthropology, Aarhus University, Aarhus, Denmark

Short title: Sharing or not sharing Uncertainties

* Corresponding author Email:

\begin{abstract}
In this article we explore the uncertainties of living in the aftermath of cancer treatment within the context of the Norwegian welfare state. Serious illnesses confront people with the uncertainty of life itself. We suggest that managing this form of existential uncertainty is inherently a social process and their considerations of whether or not to share worries are part of the everyday management of social relationships. We refer to this process of managing uncertainty and the social processes intrinsic to it as an act of 'balancing'. We draw on data from repeated interviews with 8 former cancer patients in a northern Norwegian city carried
\end{abstract}


between January 2014 and January 2015. Through our inquiry into who was involved in the participants' interpretation of bodily sensations, health and care seeking, we found that the participants were keeping most of their uncertainties to themselves. Their main argument was that they did not want to make others worry unnecessarily. On the other hand participants talked about the need and expectation that relevant others had to be informed and involved and the participants also described needing an outlet through being able to share worries. These needs and concerns were balanced within a wish to maintain 'normal everyday life' as far as possible.

Keywords: after cancer, risk, uncertainty, pragmatism, social relations, everyday life

\section{Introduction}

In this article we explore the dilemmas former cancer patients face in deciding what to share with relevant others and what to keep to themselves, as a way of managing existential uncertainties in life after cancer. We suggest that this managing of uncertainty after cancer is inherently a social process that becomes part of the everyday management of social relationships. We refer to these processes as balancing whereby concerns such as inclusion and trust are balanced with avoiding unnecessary worries and protecting experiences and conceptions of everyday life.

\section{Uncertainty amid the surviving of cancer}

Cancer patients in Norway experience cancer within a safety net that works at several different levels, including the medical, social and economic. Cancer treatment is administered in public hospitals with routine follow-up consultations in the first few years after therapy. 
Economically, the cancer patient enjoys the rights and goods of a highly developed welfare system within a country that has one of the lowest levels of inequality within OECD countries (SSB Statistics Norway, 2014). Uncertainties that are still experienced in everyday lives of former cancer patients concern dimensions of life and existence, such as expectations of living or dying, being healthy or not, and knowing how to take part in, enjoy, and fulfil a role in everyday social life (Bøhn, 2000; Loge, 2013). These uncertainties are intrinsic to life itself, but when severe conditions such as cancer are diagnosed, they become more tangible than a vague possibility.

Research has shown that existential uncertainties are often present in life after cancer, especially in terms of the possibility that the cancer may reoccur and be fatal. In her studies of information seeking in American couples where one had been previously diagnosed with cancer, Miller (2014) observed that the

challenges of cancer survivorship demonstrate that newfound health may be bittersweet. While surviving cancer treatment is good news, various looming uncertainties may prevent survivors and family from returning back to their 'normal' lives (Miller, 2014, p. 240).

Other researchers have found similar challenges. Even when tests show no sign of residual cancer, uncertainty about recurrence is often present (Lee-Jones, Humphris, Dixon, \& Bebbington Hatcher, 1997; O'Neill, 1975). In an analysis of his own general sense of existential crisis after cancer treatment, Horlick-Jones (2011, p. 890) stated that being able to function 'on a day-to-day basis necessitates suspending awareness of impending death, in order to find meaning in doing things, planning etc. After cancer this proves difficult'. The cognitive and emotional work in 'bracketing out'(Giddens, 1991) or 'bracketing off'(Brown \& de Graaf, 2013) negative outcomes is also shown in a study about time and hope amongst Dutch cancer patients who had received terminal prognoses (Brown \& de Graaf, 2013). This 
study also shows how time became a deeply meaningful value, both because it gave hope for new treatment and survival in 'future-time', but also as time being spent with family. An awareness of the importance of social relations and spending time on these is also shown by Rasmussen and Elverdam (2007) in a study of how Swedish cancer survivors relate to time:

The confrontation with death means that the future becomes uncertain and informants become more conscious of the time right now (Rasmussen \& Elverdam, 2007, p. 619).

Conceptualisations of uncertainty are often connected to the concept of risk and vice versa (Boholm, 2003). Our main understanding of uncertainty and risk in this study does not start from a focus on the risk of cancer recurrence in itself or on whether risk is managed as an objective risk or a perceived risk (Boholm, 2003) or whether the approaches to uncertainty are rational or non-rational (Zinn, 2008). Following Jenkins et al. (2005) we instead view uncertainty as a state of being, focusing on the symbolic and existential dimension of it something that a risk discourse departing from clinical risk does not fully encompass. Instead of 'risk-balancing activities' (Zinn, 2008, p. 446), we may talk about activities for balancing the state of uncertainty drawing on Jenkins (2005):

Matters of life and death are self-evidently at the heart of human existence. When sickness calls into question that existence we are confronted by the uncertainties of life. In such situations our concerns are not only with the physical body and experiences of physical pain and fragility, but also the social and symbolic aspects of life and death. These are aspects of well-being that are no less real than the body and its frailties. Sickness in particular and crisis in general pose questions of our very sense of existence and non-existence, and thus raise questions about how to deal with the uncertainties of living and the means with which we try to maneuver when the waters of life are troubled. (2005, p. 9) 
While researchers have recognised how uncertainty is ever present in peoples' lives after cancer, and how managing uncertainty becomes a part of their new life (Horlick-Jones, 2011; Jain, 2013; Lee-Jones et al., 1997), in this article we aim to develop considerations of uncertainty further by emphasising the importance of social relationships, arguing that the management of uncertainty is inherently a social process, and simultaneously the management is aiming at maintaining and protecting social relations and everyday life. Moreover, empirically departing within the ideological and cultural contexts of the Norwegian welfare state which emphasise security and access to health, in this article we argue that the way social others are involved in the managing of uncertainty reflects the manner by which careand treatment practices are highly institutionalised by biomedicine. The health care system takes care of diagnosis and treatment, yet uncertainty about outcome and future life is still present and becomes interwoven with social relations.

While drawing on the work of Jenkins and colleagues (2005), we further draw on Whyte’s engagement with pragmatism (Dewey, 1929) as a way to understand how people alleviate suffering amid uncertainty (Whyte, 1997, 2005). Whyte's focus is on what people actually do to handle situations of illness and misfortune,and through this we seek to gain an understanding of what is at stake (Kleinman \& Kleinman, 1991):

in the sense of what people are striving for, and the resources, including the meaningful ideas, with which they try to accomplish their desires. (Whyte, 1997, p. 4)

Whyte's (1997) study in Uganda found people use the means that are at hand to try to deal with illness and misfortune. Social relations are central to these approaches and can both be a source of uncertainty and threat through spirits and sorcery and a resource to gain access to means of dealing with illness and misfortune. In our study we will argue that the way former cancer patients handle their social relations, here by balancing sharing or not sharing their 
existential worries, is a means of employing 'meaningful modes of acting' (Whyte, 1997, p. 246). Social relations become central to these 'meaningful modes' also in a Norwegian context and to existential deliberations when managing the problem of uncertainty after cancer illness. In the article we refer to 'meaningful modes of acting' as acts of balancing. Balancing unfolds in a series of practices and reflections on issues such as inclusion vs protection, managing emotions in the presentation of self, and disclosure vs listening. To balance is to navigate between these concerns while caring for both oneself and one's social relations. To disclose and to share has an element of 'intentionality and deliberation, if not calculation based on the costs and benefits of exposure’ (Davis \& Manderson, 2014, p. 154). Sharing trivialities, or matters that are not sensitive or delicate are then not an act of disclosure, as they have no immediate impact on peoples' social world. In this article we will show how delicate balances of sharing and disclosure have costs and benefits, and concern existential matters at stake.

In line with Whyte we consider it important to focus on the everyday lives and practices of the situated actors. These practises are not attempts to handle the risk of cancer itself or reducing the dimension of uncertainty to the risk. They are attempts to handling life with the risk and uncertainty in a way that prevents the state of uncertainty from dominating and having negative consequences for everyday life and social relations. Being and wellbeing in the social realm concerns abstract, existential values and aspects of self that are important to us and others. These values are at stake, desired and may be lost in interaction with others if not treasured (Jackson, 2005; Jackson \& Piette, 2015). The aim of this article is to explore how the participants handle a state of uncertainty within the everyday management of social relationships through balancing the sharing of existential worries. 


\section{Methodology}

As we aim in this article to investigate the role of social relations in former cancer patients' processes of sensing, understanding and handling illness in everyday life, we needed to be able to access a method that would enable us to establish a trusting relations that would give participants a protected space sharing and reflection on their experiences. Such a space would enable us to make observations of the changes and development that took place in participants’ situations. We used a longitudinal design for our study (Johnson, 1998), with repeated semi-structured, one-to-one qualitative interviews (Kvale \& Brinkmann, 2009). Tone Seppola-Edvardsen contacted the participants and undertook initial interviews and followed the participants for one year with interviews and some joint activities. In total 41 interviews were conducted with eight participants, varying from 3 to 7 interviews per participant.

This article is based on an an analysis of all semi-structured interviews as well as field notes from participatory activities conducted between January 2014 and January 2015. We recruited participants in a northern Norwegian city. We recruited participants through family doctors who had agreed to distribute information about the project, together with a letter of consent. Initially 6 individuals responded and agreed to participate, with two more recruited during the beginning of the first half year. As we wanted to examine the social process of interpreting bodily sensations after cancer, we recruited people who had received different cancer diagnoses and who were at different stages in the post-cancer process. Our only precondition was that participants should have completed the treatment for their cancer and had recommenced a form of everyday life again, supposedly free from cancer. Due to suggestions from the family doctors, we chose not to restrict recruitment to people only in the first years after cancer, as the cancer experience might have influence on people’s life long after finishing treatment. Such an open selection also provided the possibility of gaining 
insight into different stages of life after cancer. The final participants had finished treatment between one and 10 years prior to joining our study. Their treatments regimes included surgery, chemotherapy, and/or radiotherapy. The participants were between 40 and 63 years old, with the exception of one, who was 75. All participants had children, most of whom were older and had left home; two were living with young children. Five participants were living with a partner. Two of the participants did not have paid work, and the rest worked mostly part time during the year in which these interviews took place.

We usually interviewed participants in their own home and the interviews took between aone nd two hours. The first interview was loosely structured (Kvale \& Brinkmann, 2009; Wolcott, 2005) and in it we invited participants to tell us their story about cancer. IN the follow-up interview we were more directive and used an interview guide and follow-up questions. We chose to have relatively few, open-ended questions, aiming at covering specific topics but leaving interviewees free to talk about their thoughts. We encouraged participants to talk about the physical, cognitive, and social aspects of their lives following cancer treatment, covering recent activities the interviewee had engaged in, who he/she had spent time with as well as more existential matters about life satisfaction, or issues, thoughts or emotions that had been preoccupying them. We also asked about more physically-oriented issues such as health, sensations, and symptoms. If participants talked about unpleasant sensations or worries, we asked if these had been discussed with anybody, and to what extent these had been addressed. We also invited participants to complete health diaries and the draw of social- and geographic maps (Aquist, 2003; Hägerstrand, 1985). These additional sources of information were mainly to provide the context and additional information on participants everyday life activities. Tone Seppola-Edvardsen also took part in leisure- 
activities with some of the participants to deepen our insight into everyday concerns (Rubow, 2003, p. 243).

As the sample was dependent on who the family doctors decided to give information to about the project, and who then decided to take part, it is likely that people who regularly saw their family doctor, and who experienced problems in life after cancer were likely to become participants. The sample is therefore not random or representative of all who have finished cancer treatment. These individuals did provide an account of the uncertainties and dilemmas of life after cancer and how these dealt with these uncertainties and reengaged with their everyday lives. Thus we see the study as providing insight into how individuals deal with severe illness and/or health crises and such insights should be generaliseable. Thus we seek to provide insights into the values and concerns at stake and how these are handled. The longitudinal dimension facilitated a much deeper grasp and analysis of each participant’s situation.

All interviews were recorded and the first-round of interviews were fully transcribed. Later interviews were recorded, partly transcribed and/or further considered through field notes. Field notes were also made after interviews and participating in activities. We analysed data both by categorising and contextualising (Maxwell, 2012) as an abductive, ethnographic analysis. We sorted data into broader themes, as for instance sensations, worries and wishes, handling, social arenas and rationales. The themes referred to meaningful units in the data and were connected to our research interest in the understanding of life after cancer, uncertainty and social relations. We used drawings and displays (Maxwell, 2012) to get a grasp of the overall picture, for example by finding similarities, connections and discrepancies, such as who would be told about what worries, who would not be told anything, and what arguments were used. During the analysis phase we consulted literature on different theoretical approaches, finding that frameworks rooted around existential uncertainty and pragmatism 
resonated with the empirical findings, thus offering theoretical purchase in unfolding what at an intersubjective level is at stake when living with cancer. Simultaneously we moved back and forth between empirical findings, categories and theories to nuance and refine our understandings.

The study was based on informed consent from all participants, who could withdraw at any time. None did and many stated that their participation had been of value to them. All material was anonymised and archived according to the current established procedures. All the names used in this article are psuedonyms. The overarching project has been presented to the relevant Ethical Committee (REK) and found not to be within their jurisdiction as a health scientific project. It has also been reported to the Norwegian Data Protection Authority.

\section{Findings}

\section{Dilemmas of sharing}

The dilemma and challenge of how much to share with others about their existential uncertainty in the cancer situation, was evident in the lives of the participants in our study. This might be seen as an example of the more general dilemma of what to tell and not in social relations, as noted by Davis and Manderson (2014). Sharing stories and thoughts about our lives is a part of building and maintaining social relations, but sharing can just as well be framed in terms of:

that which is not and cannot be told, underlining the interpretive and ethical challenges of what to reveal and what not to, and how to interpret what is revealed and what may not have been. (Davis \& Manderson, 2014, p. 156; Squire, 2015) 
Britt (58 years old) explained that sharing uncertainty with somebody could help, as it might ease worries.

Especially on a day where you feel weak or anxious, it feels good to be able to talk about it, because when you have spoken, maybe the other person can put it into perspective so that the worry is eased (Britt).

She sometimes told her husband and two friends, the ones she usually talked to, she said. But there were limits to sharing as well, 'as others could be affected by it', she said. Frequent uncertainties and worries about the return of 'her cancer' could arise with unpleasant or unusual bodily sensations. Any pain and unpleasant sensations made her worry about cancer relapse or a worsening physical state. She also worried that her death would have a major impact on her close ones, especially her 26 years old son, with whom she had a tight bond. Her bodily changes might 'just' be the result of her treatments, like pain or fatigue, or represent the innocent and unrelated issues like infections or merely a bad day. But she was reluctant to share. She noted that this was a general concern of her as she was: 'keeping the small things to one-self'.

Such worries were ones that the participants often did not want to bother anyone else with. Eva (59 years old) commented: 'I don’t want to start people worrying unnecessarily. Well I don't think there is any point in it'. Worries of this sort seemed to have the potential to disturb everyday social situations by evoking uncertainty about the future. Britt (58 years old) described how she had learnt to keep worries to herself in order to give room for ordinary everyday life and keep the future at bay: 'You in a way have to learn to carry on your normal everyday life in it.'

After finishing treatment, the participants longed for and expected to be able to get back to their normal, (pre-cancer) everyday life. During their illness they had put their life 'on 
hold' as some expressed it and subsequently they wanted to resume their normal life, carry on where they had left off. At that point, everyday life represented a known and ordered existence that stood in stark contradiction to the chaotic experience of illness (Gullestad, 1989, p. 23). Lillehorn (2013) in her Swedish study on the meanings of breast cancer in a life context also observed this desire to return to normal everyday life noting that the women in her study:

strove to regain familiar structures and ordinary routines in their everyday lives since connectedness and meaning was given by everyday life .(Lillehorn, 2013, p. 67)

Ingrid talked about her high expectations for life when finishing cancer treatment:

So then my life was supposed to start again. I was terribly optimistic and..., felt that I could manage whatever. I had, in a way, beaten cancer and..., felt that I had an awful amount of power and strength.' (Ingrid, 40 years old)

But like many former cancer patients, Ingrid noted that 'normal life' after cancer was, in reality, a 'new normal' (Balmer, Griffiths, \& Dunn, 2014) where fatigue and physical restrictions, as well as worries about cancer recurrence, made it impossible to maintain the activities and obligations ordinarily undertaken before their diagnosis. Ingrid had had to adapt her ambitions and expectations for her life, with the result that her new aims had a different focus.

My aim is to have a good life. To feel a good quality of life, and that's what I do when I take care of myself, and fill my life with things that are meaningful. Which is a job and family and that kind of thing - those make me happy and satisfied. And it is a goal for me to be a good mother. I think that is the most important task of my life, being a 
mother. To give my kids a solid and happy start in life. (Ingrid, 40 years old)

Ingrid pointed to the importance of work and family and highlighted the importance of being a mother, caring for her children. These are values that are connected to everyday life. By limiting disclosure, a certain sensitivity towards others was administered, that is in order to maintain social relations and everyday life it was seen as necessary to balance the different demands and considerations as to what to share - depending on the context and the relationships involved. Ways of accomplishing this task shed light on what Davis and Manderson when discussing life after cancer therapy have have referred to as:

the emotional and relational labour that comes with family life, parenting, workplace reputation, and the biographical shaping of the self. (Davis \& Manderson, 2014, p. 159)

In the following examples we will show how the participants managed this balancing strategy in different social contexts and what was morally and personally at stake. The main concerns that stood out were a care for the self, for social relations and for everyday life.

\section{Protecting your close ones - avoiding unnecessary worry}

When somebody falls ill with cancer, those closest to them are also affected. Both participants and their families were afraid of having the cancer trauma repeated, and the subsequent possibility of losing one another. The participants were especially concerned about the possibility of not being around for their children in the future. Eva, a 59 year old nurse who had been sick with breast cancer, often talked about how important her family was, especially her adult sons and husband but also other close family. In her first interview, she observed out that if someone in the family had to get cancer, then she was glad that she was the one who did. She told us that the thought of someone else in her family getting cancer upset her and 
would have been unbearable for her. However she did reflect that it was a great shock and sorrow to her sister and mother in law when she got cancer and she ended up having to be the strong one, and having to comfort them, instead of receiving the support that she had initially expected. This was an experience she sharee with other participants who explained why 'not making people worry unnecessarily’ was important. This was a frequently cited rationale for with holding some information, especially from the oldest and the youngest, whom participants said they had to protect.

Britt who was 58 years old and who had been ill with ovary cancer, had never told her mother who was 95 years old about the cancer. Her mother lived in a nursing home and Britt visited her regularly. At the time of the interview Britt still was not sure whether her mother understood what had happened. Britt talked about a visit to her mother after she has had her uterus removed:

So I was there, but I couldn't really straighten up when I entered her room, so she wondered why I was walking so bent and crooked. So I just told her that I'd had my uterus removed. I somehow could... could not bring myself to say anything about... 'Oh, well, I did too', she [her mother] said 'Then you must be careful to get some rest'.

Later, when she started her chemotherapy, Britt had to explain to her mother why she could not visit as often, She told her mother:

'I will probably not come as often at the moment, because I've had to take some medicine because I have these cells dividing.' So I used this word instead. I don't know if that was right or wrong. 'So I get these medicines and then I become a bit weak.' (...) I don’t know if she realised anything, but I noticed one time (...) that she was looking at this spot (a spot without hair on her skull), but she didn’t say anything..., no, so... it was a bit strange. But at the same time I think that I don't need to discuss it so much 
with her. But you know, somehow, we are mothers, so we have some antennas activated. Even when you are old.

Britt did not want her mother to know about the cancer, but she still had to give some plausible explanation about her state of health and to account for her awkward, bent over walk and her less frequent visits. While she avoid lying, she was careful what she said, using slightly ambiguous wording. When she reflected on how she had managed the situation, she was not sure she had done the right thing. She suggested that her mother may have suspected that she was not being completely truthful and that may have introduced some tension into their relationship. However Britt suggested that even if her mother did suspect the truth some things were best left unsaid. Britt's concern was to protect her mother and to enable her to enjoy what remained of her life, without having to worry and be upset about. Britt said she had opted not to let uncertainty dominate her time with her mother and what could have been some of her last visits to the nursing home. Britt talked about her decision to pro-actively manage the impact of the uncertainty caused by her illness by not involving her mother in her own uncertainty. This is an example of balancing and controlled disclosure, both verbally and bodily as it illustrates the dilemmas 'framed by that which is not and cannot be told', (Davis \& Manderson, 2014, p. 156). The unsaid is left to be conjecture. Britt's case show that what cancer survivors are willing to share with their families is situation dependent and presents an ethical challenge as they try to make the 'right' decision about the rights and wrongs of disclosure.

While Britt expressed some doubt about her decision-making, her management strategy had inadvertently generated fresh unease and uncertainty to the relationship. However meaningful her mode of managing was to Britt, it also entailed a possible reconfiguration of a social relation. The same dilemma of disclosure could be seen in attempts 
to protect the youngest family members from uncertainty. Ingrid a 40 year old talked about telling her youngest eight year-old daughter about her cancer:

The youngest has started understanding more, and is shocked by the fact that mum has been ill. [She asked me] 'Mum, why did you get cancer?' She had to talk about it and cry a little. [She also asked me] 'Can you become ill again?’ [I replied] 'No, now I am well.’

Ingrid reassured her eight-year old daughter who was born after her illness that she was now well. Ingrid said that she death with her daughters anxiety about the possibility of the cancer returning by saying that she was now healthy. Ingrid indicated that she minimised the risks to protect her young daughter from uncertainty and from the worries that would undoubtedly follow, so that 'normal' everyday life could go on. Ingrid did not reflect on whether this was the right decision and whether she was telling the full truth, she just reported she had made a choice to deal with the situation in this way.

Some of the participants reflected that the dilemma was greater with older children in protecting them from worry while satisfying their expressed desire for honest disclosure and information. Britt (58) recalled a conversation she had had with her son who was then in his late twenties.

He asked if I was telling him everything... 'Yes' I said, 'I am'. Then he asked again...'Well are you sure that you're telling me everything?' -'Yes' I said, 'I am'. So now I've decided that from now on, however things are, I will tell him... but I haven’t told him that my blood samples are now at 29 [Britt refers to a test that measures levels of a 'tumour associated protein' that possibly indicated she had ovarian cancer], because I don't think that's something he needs to know. If it becomes 42, then I'll say something like 'now I have to go to this, or that examination', but not yet. One doesn't 
need to create upset before necessary. No... I can feel that one wishes to protect the kids as much as possible. (Britt, 58)

Britt indicated that her son felt uncertain about the situation itself and about the extent of disclosure from his mother and her discussion of the situation suggested that to obtain some form of certainty, he tried to find out 'what is revealed and what might not have been' (Davis \& Manderson, 2014, p. 156). Britt had promised her son that she would tell him 'everything', but, of course, it was not clear exactly what everything covered, for example it did not cover possible ovarian cancer. In her interviews, Britt talked about her dilemma, she wanted to respect her son's wishes as an adult, his right to be informed and maintain their close relationship but she also wanted to protect him from the kind of worries that might be ‘unnecessary’. Her mechanism for managing uncertainty enabled her not to disturb her interaction with and relationship with her son, based on her judgement as to what constituted a tangible medical concern, worthy of disclosure. However, questions over how to share or not share worries could still potentially reconfigure her relationship with her son despite intentions to preserve and protect the relationship and their normal everyday life and interaction.

When participants talked about their relationships with their partners, it was clear that the issues of what to keep to oneself and what to share were complicated and managed at different levels. Participants talked about the concerns they felt they could share, those that would be understood without being discussed or ones that they had to deal with themselves. Erik who was 55 years old and lived with his wife, adult daughter, and her partner talked about how his wife had been of great support during cancer treatment. However he also observed that she was quick to point out to him that he should not get preoccupied with his own problems but had to consider the rest of his family as well. While we were undertaking the research, Erik was often ill due to an immunodeficiency caused by his cancer treatment. 
Each time he became ill, he started worrying that it could be a cancer relapse. When asked about sharing his worries he had difficulties explaining what he shared and why, giving an idea of how difficult and ambiguous this balancing act was.

I don’t speak to many about it. I usually keep it inside that I have thoughts about..., Now for example, when I have been ill, and then cancer... and... But she knows about it [his wife]. No, she doesn't get to know everything... No, such a burden... (...) I try at least not to worry the rest of the family, kids and... But I am at least not..., well, I don’t think so at least..., that I am a melancholy person. I try not to be.

Erik described how he tried to prevent uncertainty from dominating his social interaction with his family. However he was aware that even though he did not share all worries others, especially his wife, was aware of them. Erik said he would tell his wife 'I wonder what this is...' signalling a worry and she sometimes signaled similar worries for example asking him: 'Have you taken your temperature?' However it was clear that this topic was not explicit or thoroughly discussed until later, when the unpleasant sensations were shown to be something other than cancer. Both Erik and his wife handled uncertainty by a form of 'careful' talk (Whyte, 1997, p. 217) and a shared understanding awareness that did not let the cancer dominate their lives.

Other participants also talked about the best way of handling worry was not to mention it too much as talking about worry did not necessarily help and could make things worse. Ingrid, who was 40 years old, for instance, had agreed with her husband that he could not do anything to help, he just had to let her 'get on with it' when the anxiety was at its worst. As she said: 'He can’t help. Nobody can help me. In a way, I just have to get on, on my own.' She said that talking about it scared her husband and made her own worries more concrete. Also Britt said that her husband had problems coping with her worries and that he became irritable when she talked too much about them: 
Then [when he became irritated] I understood that I had to learn to be more quiet. Of course, you have to be a bit considerate about how much you... You in a way have to learn to carry on your normal everyday amidst it.

The participants talked about the ways in which they trained themselves not to make their worries and concerns a frequent topic of discussion, as this would only serve to validate them and make them more tangible to others, and, at the same time, possibly jeopardise their everyday social life. Drawing on existentialist philosophy, it is possible to argue that the worries or uncertainties acquired a reality through the meaning the participants gave them. When the participants started talking about them, they became much more 'real' than when they only existed more implicitly between them. Keeping uncertainties unspoken, became a way to manage them (Whyte, 2005). This left more room for other activities, like enjoying life together, and caring for the wellbeing of those closest to them (Jackson, 2005). Still some sharing was needed, as older children, partners and other trusted ones, expected to be informed and included as part of the relationship. In this context, decisions about what to confide and to whom gave rise to another type of uncertainty, both about what to share, and how to formulate it (Davis \& Manderson, 2014). Such subtle considerations further define new subjectivities pertaining to the cancer patients themselves and a change in the intersubjective relationships within the family. As we have seen, social relationships are not left untouched by uncertainties of cancer, nor are the cancer patients themselves.

In the next section we move to consider situations where sharing is less a matter of worrying other people than managing an acceptable presentation of the self by controlling emotion. Although other considerations and values were seen to be at stake, it was important to maintain social wellbeing and the ability to participate in daily life, also outside the family. 


\section{Managing the self}

In this section we consider situations where sharing is less a matter of worrying other people than managing an acceptable presentation of the self by controlling emotion. Although other considerations and values were seen to be at stake, it was important to maintain social wellbeing and the ability to participate in daily life, also outside the family. Participants noted that after their cancer treatment their physical appearance and cognitive state often showed more of their suffering than they wished to share with everybody. In some ways their embodied selves 'gave them away'. Many participants experienced difficulties in controlling their emotions after cancer, a kind of 'emotional incontinence' as one described it. The participants recalled how irritability, anger and sorrow had become more difficult to control. Telling their story could evoke emotions perceived as inappropriate for the situation, which compromised respect and dignity. Managing emotions 'down' was seen as necessary to avoid upsetting social situations by respecting the relevant 'feeling rules' (Hochschild 1979). This was mostly evident in participants' talk about their work situations but also evident in their discussion of iother public situations, dominated by less personal relations, as the participants on occasions expressed concern about how others might perceive them.

Erik who was 55 talked about how, when he had completed his therapy, he initially had problems meeting people he knew. When in town, he avoided walking in the high street, as he did not want to meet too many acquaintances. He did not like them seeing him in his diminished physical state and he found it difficult to talk about his illness. At the time of the interviews he was working part time because of lasting effects following his therapy and he struggled with accepting a less important role at work. Before his illness he had spent considerable time on physical exercise and was used to being extremely fit and active outdoors. He worked in a male dominated profession where being physically and mentally 
strong was highly valued and occasionally necessary. In recounting one particularly traumatic episode Eric observed:

And meeting people. That was hard. Meeting people you knew, that was really hard. (...) I did not want to talk about it. And tears... Well, I am the kind that can be moved, but... it could be a song, or a film on the TV or something that was said and then I felt, oh shit, here come the tears! Also at work. (...) And I could not stop it. And I was so angry with myself. I dropped by at work and I got a scolding from my wife afterwards, because I had dropped by at work. [She said] 'Why, when you know it?!' Well, and I sat down at the coffee corner at work. I was there to hand in a sick leave form or something. I was in the process of coming back and good old colleagues came and sat down. So we were sitting around the table talking, and then... Well, we touched upon a topic connected to the illness, and before I knew it, started visualising things and it brought back feelings. Shit! And then the tears came. And then they started... my colleagues just stood up, one by one and left. Suddenly I sat there alone. It was their way of dealing with it. (...) So there I sat, ok... and I was so angry with myself. Why? Why didn't I just hand in the form and leave? Why did I get involved? Well, because I wanted to keep up on things, hear news. And then I sat there alone. So I put my cup in the dishwasher and I sneaked out the back door. After that I didn't go back for three months.

Erik talked about how meeting people was in itself a challenge given his physical appearance and fitness, in which he had taken so much pride, was now letting him down. The extent of his decline just served to reinforce how much he had lost due to his illness. Meeting work colleagues also challenged Erik's sense of self, which was tied up with his physical and emotional strength. Not only had he declined physically but he also suffered a loss of mental resilience by failing to control his emotions. He was working in a male environment where 
part of the job was to be able to control people and tense situations. Being in control of oneself physically and mentally was seen as a considerable attribute. However, Eric's emotions had betrayed his fragility, which then caused embarrassment. Eric's audience then disclosed their attitude (Davis \& Manderson, 2014) towards his emotional outburst; they became embarrassed or expected Erik to be, so they left him alone. This could be seen as a way of caring for Erik and their relationship to him, protecting him by leaving a situation that threatened his dignity or presentation of self (Goffman, 1978) but at the same time, Erik talked about it as their lack of recognition of his emotions and the existential uncertainty that he faced. After that episode Erik managed his emotional uncertainty by being very cautious in how he discussed his illness. He described speaking about it only in very vague, general terms or not talking about it at all. Other participants similarly recalled work situations where managing emotions had become more difficult to manage and thereby threatened their sense of self, and control of their presentation of self. They said that irritability, anger or lack of self-esteem had made it more difficult to handle conflicts for instance, and care situations at work evoked emotions that had been suppressed during illness. Ingrid who was 40 years old had asked her employer if she could be excused from caring for a dying cancer patient with young children. She recognised that this was a demanding task for all her colleagues, but she noted that since it brought back so many memories and emotions connected to her own cancer experiences it would be difficult for her to maintain the professional stance she would need if she were to provide good and professional care. She also acknowledged the ways she felt her own experiences had enhanced her understanding of the patients she worked with, and thereby made her a better caregiver. She and other participants mentioned a balancing in care situations of how much to disclose about their own situation: on the one hand to establish rapport, and on the other to prevent their story from dominating or disturbing by evoking unwanted emotions in themselves and the other. 
Participants talked about managing emotions in public or semi-public space (Hochschild, 1979), to prevent the escalation of conflict or causing embarrassment by showing or generating emotions that made the situation difficult to handle. They aimed to balance what they shared or disclosed about their uncertainty and suffering. This can be seen as an example of participants 'managed their own emotions in order to manage the emotions and responses of others' (Black, 2011). Such balancing helped them remain or to function within the social contours of everyday work life.

In other relations, keeping emotions under control in the sense of presentation of self, was of less concern than acknowledging the significance of a relationship. In these cases, the 'balancing' was managed in securing reciprocity and wellbeing.

\section{Maintaining reciprocity and wellbeing in social situations}

Most participants talked about the importance of their contact with their friends. For example Eva talked about how she spent her days off work meeting old friends for a cup coffee or a meal in a restaurant. When normal levels of activity were impossible, the small things became important. John who was 53 years old stated that he always tried to get something good out of his days and that the small things were most important to him, like 'Just meeting somebody and being able to have a good chat'. John was single and lived alone. He often expressed feelings of loneliness and a certain degree of 'separation' from life after cancer. He did not have his old physical strength and thereby also had lost some of areas of his social life connected to work and outdoors recreation activities that he valued. Not being able to take part in activities, both work and leisure related, were mentioned as a loss by many participants, not least in terms of their social aspect. Maintaining a good relationship with remaining friends and colleagues became increasingly important, as did the need to actively manage the influence of cancer and its inherent uncertainty within these relations. 
Participants talked about the importance of not letting cancer become the main topic of conversation in social contexts. As Britt noted: 'You have to be careful not to wear people out. To be able to push things aside and talk about other things.' When she was worried, talking to somebody about it however often helped. Simultaneously she did not want all conversations to circle around her uncertainty and suffering, although she thought that everyone should have the patience to let others have some extra time talking about their problems when experiencing difficulties. On the other hand she also expressed the view that seeing friends was a good way of getting her mind off her worries by talking about other topics. In these relationships a form of reciprocity (Mauss, 1950) was attended to maintain the wellbeing in the social situation. Participants described the ways they expected that close friends would expect some reciprocity in disclosure or sharing among them, to affirm and maintain their emotional connection (Davis \& Manderson, 2014) but on the other hand, the wish and need to talk about ones' own life was weighed against others’ wishes or needs to talk about theirs. When the participants limited the time spent on the topic of cancer, it demonstrated care for the healthy listener as well as themselves, who were happy to spend 'head-space' away from their worries by talking about other things. Uncertainty was managed by not letting cancer worries dominate the social situation, and thereby keep up everyday social interaction with friends.

Participants talked about the difference between talking to friends and talking to individuals who had experienced cancer with whom they shared a greater mutual understanding. Britt reflected on interaction with another cancer survivor in the following way: 'We both feel that it is good to meet, as we understand each other. We don’t have to say much.' Nora who was 63 years old recalled a meeting with a colleague who had just got a cancer diagnosis and who apparently needed to talk to somebody who could understand. She reflected on the equality of the interaction: 
She [her colleagues with the cancer diagnosis] felt that she had now found somebody that she could talk with on an equal basis. So it became a kind of... dialogue.

Nora saw the understanding as being mutual, a lot of things did not have to be explained as they shared similar experiences. In this way it became a dialogue where both were in the position of telling and understanding. However even in this type of conversation it is clear that there had to be balancing work. Nora described as taking place to the extent that there was an acknowledgement of the vulnerability that lies in uncertainty, and how disclosure can ameliorate this. However Nora suggested that disclosure of future unpleasantness might be withheld in order to protect the other:

'When she started talking about chemotherapy, and how she felt, I thought I should really say as little as possible. We are so different. Some react like this, and... some become really ill. (Nora).

When participants talked about cancer treatments they noted that they could affect people differently but that a positive outlook on the future was important. The need to maintain courage despite the uncertainty, hoping that things would get better, was seen as paramount. Understanding the situation made it easier to be careful in managing each others' emotions, which made it easier to protect each other's wellbeing in present time.

\section{Discussion: Balancing gains and risks of disclosure}

Our analysis of the ways in which the study participants talk about their experiences and interactions after cancer indicate that they struggle with existential uncertainties and confirm the findings of other studies (for example Horlick-Jones, 2011; Lee-Jones et al., 1997; Muzzin, Anderson, Figueredo, \& Gudelis, 1994; Stoller, 2004). The participants talked about 
how they had come to appreciate and value aspects of life differently, and in this way had modified their 'experience and life world' as the unthematised horizon of knowledge that we as human beings experience and act upon in relation to our culture and society (Gullestad, 1989). Social relations and everyday life now assumed a greater prominence, as also shown by Rasmussen \& Elverdam (2007) in their study of how cancer survivors experience time. Rasmussen \& Elverdam found that participants in their study had become more aware of living in the present and not spending time on things they found unimportant. Spending time with family and friends was now prioritised. These findings are in line with our own, but in addition our data illustrate how the participants in our study talked about striving to stay in their present, everyday life situations. Central to this was being able to maintain their roles in important relationships to family, friends and colleagues, in the middle of handling uncertainty after cancer.

The values of social relations and everyday life might well represent aspects of life described by Jackson $(2005 ; 2015)$ as 'forms of reason' or 'forms of life', that is those that are existentially most imperative to us and are seen as being:

at stake in the critical moments that define our lives, notably love, mutual recognition, respect, dignity, wellbeing. (Jackson, 2005, p. xxix)

It was clear from our conversations with the participants that the 'critical moments' were at play in everyday social settings and interactions, where they balanced the sharing of thoughts with others. Maintaining hope by not sharing unnecessary uncertainty or letting cancer disturb daily life, was strived for in order to protect the social situations and relations at stake. The way the participants kept worries and uncertainties to themselves can be seen as a form of 'bracketing out' (Giddens, 1991) or 'bracketing away' the thoughts of negative outcomes of cancer illness in the future, as described by Brown and de Graaf (2013) in their study about expectations and construction of time among cancer patients with limited prognoses. The 
'bracketing off' of negative outcomes described in Brown and de Graaf's study was done in order to keep up hope and plans for 'future time'. In cases where little hope considered, the future was 'bracketed off' to be able to enjoy the moment and the present day. Similar findings are evident Alaszewski and colleagues (2006) in account of the ways in which stroke-survivors adjust to life acre their stroke.

The cancer patients in Brown and de Graaf's study were living in a different situation to those in ours. In our study the participants were classified as 'cured', they had finished treatment, and tests had shown no remaining signs of cancer. They all expressed uncertainty about the future but seemed to think of their 'future time' as probable and to be worried as overreacting. As far as they practiced 'bracketing off', it was less a matter of keeping up a fragile hope than a matter of not letting the probable unnecessary worries and uncertainties about the future disturb the everyday. The keeping of worries and uncertainties to oneself might be seen as a bracketing off of certain topics in social situations, where the aim is to prevent significant others from being disturbed by the uncertainty and this being a hindrance to living a normal everyday life. But as we have shown sharing and inclusion were also very much part of social relations and social situations and the term bracketing off might not cover all nuances in the balancing that is done in these social situations, as inclusion is also central to balancing.

We also observed one aspect of 'balancing' which was about including others in one's life, accepting that others were close enough, old enough, resilient enough, able to provide support or simply able to listen to what was shared as a good colleague, friend or relative. Another dimension of balancing was about protecting others from worries and uncertainties that could not be shared without the risk of disturbing their daily life situation. In this context sharing was framed by 'that which is not and cannot be told' (Davis \& Manderson, 2014, p. 156; Squire, 2015), depending on the social situation and relations involved in it. 
For families and those in close relationships, the former cancer patients strove to uphold a sense of feeling secure or safe and uphold an 'ordered everyday life' (Gullestad, 1989). In this way it was possible to concentrate on the daily organisation of tasks and activities and to take part in daily social situations. Their reflections on issues such as the ‘need to know’ or 'unnecessary worries’ were relationship dependent. The participants felt an obligation to protect very young or old while older offspring, partners, and other close relatives, were in a more equal dynamic with the participant and did not need such protection. In these relationships careful sharing still existed, with an embargo on the disclosure of 'unnecessary worries' that might turn out to be unfounded. Balancing was needed in terms of what to share, and how to disclose it. Nonetheless, these balancing 'equations' were still difficult, and mutual understanding seemed to be key to any satisfactory outcome.

The managing of emotions was often implicit in these accounts of balancing but emotion work was more explicitly referred to regarding participants’ interactions with colleagues (Hochschild, 1979). They talked about managing emotions so that they did not interfere with, or erode their status in terms of the performance required in daily work situations. On the other hand, the participants also talked about a desire to share their stories as part of building and maintaining social relations and as a way of helping others better understand their changed circumstances. Interactions with friends were often conducted with the concern of not exhausting the good will of these friends. Conversations could not always be about illness and worries and participants referred to needing to listen to other stories and share other interests. However friends might wish, and expect, to be informed and included in the cancer experience, with former cancer patients finding it helpful to have somebody outside of the immediate family and work with whom to discuss their concerns. A pragmatic way of handling uncertainty in these situations was by letting a sense of reciprocity guide the 
balancing of sharing and not sharing.

\section{Conclusion}

Balancing what to share and what not was a meaningful mode of acting as it was an important strategy in managing the state of living within existential uncertainty, without letting it dominate social situations. This way former cancer patients were caring both for themselves and others. What was at stake, was a balancing of social relations to be able to preserve these and to stay in or get back to 'normal life' or the everyday, as it existed before their cancer diagnosis. As a consequence, our aim has not been to show how the participants handled the risk- or time-dimension of uncertainty in itself see for example (e.g. Alaszewski et al., 2006; Brown \& de Graaf, 2013), but how they handled, or rather protected, social relations and everyday life within the inherent uncertain situation after cancer. The everyday was not primarily a representation of the time-aspect, as present time or a moment of being, but a contexts for social relations and a basis for living a good life. What did not seem to be at stake was a focus on personal growth or 'remaking the self' as other studies have found, for example Bell (2012). This does not mean that none of the participants had made lifestyle changes, for instance increasing physical activity, eating more vegetables, or practicing meditation. Rather, we found that the aim of these activities seemed to be more oriented towards helping the person back to 'normal life' after cancer, so much as creating a new and better version of the pre-illness self. In this sense we did not find evidence of influential discourses of a new cancer identity (Jain, 2013).

\section{References}


Alaszewski, A., Alaszewski, H., \& Potter, J. (2006). Risk, uncertainty and life threatening trauma: Analysing stroke survivor's accounts of life after stroke. Qualitative Sozialforschung/Forum: Qualitative Social Research, 7(1), Art 18., http://www.qualitative-research.net/fqs-texte/1-06/06-1-18-e.htm

Aquist, A.-C. (2003). Everyday life and urban planning: an approach in Swedish human geography: Ashgate.

Balmer, C., Griffiths, F., \& Dunn, J. (2014). A ‘new normal’: Exploring the disruption of a poor prognostic cancer diagnosis using interviews and participant-produced photographs. Health:, 1363459314554319.

Bell, K. (2012). Remaking the self: Trauma, teachable moments, and the biopolitics of cancer survivorship. Culture, Medicine, and Psychiatry, 36(4), 584-600.

Black, R. J. (2011). Living with dying children: the suffering of parents. University of Kent.

Boholm, Å. (2003). The cultural nature of risk: Can there be an anthropology of uncertainty? Ethnos, 68(2), 159-178.

Brown, P., \& de Graaf, S. (2013). Considering a future which may not exist: the construction of time and expectations amidst advanced-stage cancer. Health, risk \& society, 15(67), 543-560.

Bøhn, M. (2000). Rehabiliteringsomsorg for kreftpasienter : motivasjon og livsmot på veien videre. Oslo: Kommuneforl.

Davis, M., \& Manderson, L. (2014). 10 Contours of truth. Disclosure in Health and Illness, 153.

Dewey, J. (1929). The quest for certainty (Vol. 4): Minton, Balch New York.

Giddens, A. (1991). Modernity and self-identity : self and society in the late modern age. Cambridge: Polity Press.

Goffman, E. (1978). The presentation of self in everyday life: Harmondsworth. 
Gullestad, M. (1989). Kultur og hverdagsliv: på sporet av det moderne Norge: Universitetsforlaget.

Hochschild, A. R. (1979). Emotion work, feeling rules, and social structure. American journal of sociology, 551-575.

Horlick-Jones, T. (2011). Understanding fear of cancer recurrence in terms of damage to ‘everyday health competence’. Sociology of Health \& Illness, 33(6), 884-898.

Hägerstrand, T. (1985). Time-geography: focus on the corporeality of man, society, and environment. The science and praxis of complexity, 193-216.

Jackson, M. (2005). Existential anthropology : events, exigencies and effects (Vol. vol. 11). New York: Berghahn Books.

Jackson, M., \& Piette, A. (2015). What is Existential Anthropology? : Berghahn Books.

Jain, S. L. (2013). Malignant: How cancer becomes us: Univ of California Press.

Jenkins, R., Jessen, H., \& Steffen, V. (2005). Matters of life and death Managing Uncertainty: Museum Tusculanum.

Johnson, J. C. (1998). Research design and research strategies. Handbook of methods in cultural anthropology, 1, 131-171.

Kleinman, A., \& Kleinman, J. (1991). Suffering and its professional transformation: Toward an ethnography of interpersonal experience. Culture, medicine and psychiatry, 15(3), 275-275.

Kvale, S., \& Brinkmann, S. (2009). Interviews: Learning the craft of qualitative research interviewing: Sage.

Lee-Jones, C., Humphris, G., Dixon, R., \& Bebbington Hatcher, M. (1997). Fear of cancer recurrence-a literature review and proposed cognitive formulation to explain exacerbation of recurrence fears. Psycho-Oncology, 6(2), 95-105. 
Lillehorn, S. (2013). Betydelser av bröstcancer i ett livssammanhang. Umeå: Umeå universitet.

Loge, J. H. (2013). Kreftoverlevere : ny kunnskap og nye muligheter i et langtidsperspektiv (2. utg. ed.). Oslo: Gyldendal akademisk.

Mauss, M. (1950). 1990. The gift: The form and reason for exchange in archaic societies.

Maxwell, J. A. (2012). Qualitative research design: An interactive approach: An interactive approach: Sage.

Miller, L. E. (2014). Uncertainty management and information seeking in cancer survivorship. Health communication, 29(3), 233-243.

Muzzin, L. J., Anderson, N., Figueredo, A., \& Gudelis, S. O. (1994). The experience of cancer. Social science \& medicine, 38(9), 1201-1208.

O'Neill, M. P. (1975). Psychological aspects of cancer recovery. Cancer, 36(S1), 271-273.

Rasmussen, D. M., \& Elverdam, B. (2007). Cancer survivors' experience of time-time disruption and time appropriation. Journal of advanced nursing, 57(6), 614-622.

Rubow, C. (2003). Samtalen: interviewet som deltagerobservation. Ind i verden: en grundbog i antropologisk metode.

Squire, C. (2015). Partial Secrets. Current Anthropology, 56, S000.

SSB Statistics Norway. (2014). Indikatorer for bærekraftig utvikling, 2014. Utvikling i inntektsulikhet.

Stoller, P. (2004). Stranger in the village of the sick: A memoir of cancer, sorcery, and healing: Beacon Press.

Whyte, S. R. (1997). Questioning misfortune: The pragmatics of uncertainty in Eastern Uganda (Vol. 4): Cambridge University Press. 
Whyte, S. R. (2005). Uncertain undertakings: Practicing health care in the subjunctive mood. Managing uncertainty: Ethnographic studies of illness, risk and the struggle for control, 245-264. In: R. Jenkins, H. Jessen and V. Steffen eds. Managing Uncertainty: Ethnographic Studies of Illness, Risk and the Struggle for Control: Museum Tusculanum

Wolcott, H. F. (2005). The art of fieldwork: Rowman Altamira.

Zinn, J. O. (2008). Heading into the unknown: Everyday strategies for managing risk and uncertainty. Health, risk \& society, 10(5), 439-450. 